\title{
Recent and emerging work in music technology in Southeast Asia
}

\begin{abstract}
Music technology work in Southeast Asia faces challenges unique to this region. Economic, religious and cultural factors hinder its progress. Despite these factors, pockets of development have occurred, most notably in Singapore and Malaysia. Academic programmes have been introduced; strides have been made in research and development; and commercially viable music technology products have been invented and marketed. Various centres in the region are active in music technology-related work: the Music Department at Universiti Putra Malaysia, the Electronic Music Lab at the National University of Singapore, and Creative Resource at the International Business Park in Singapore. The First International Music Technology Conference in Southeast Asia held in Kuala Lumpur recently received lukewarm response in terms of turnout and contributions. People from this region have produced a relatively small number of music technology-related publications. Music technology work in Southeast Asia can thus be said to be in its infancy with small but significant steps being taken to expand; however, for the region to become a major contributor on the international level, the various hindrances identified will need to be addressed and overcome.
\end{abstract}

